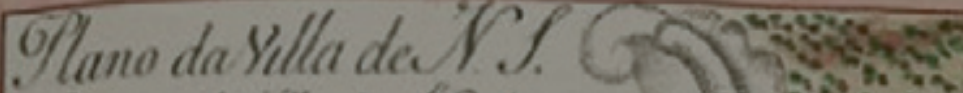

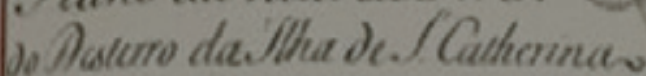

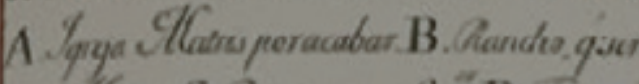

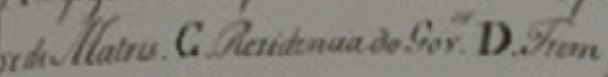

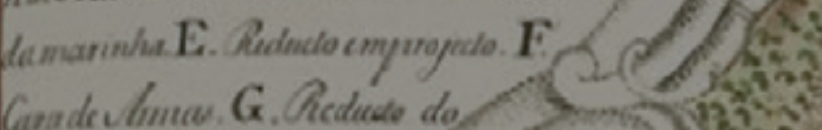

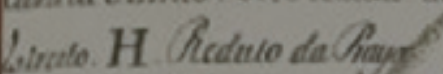

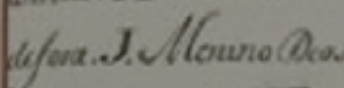

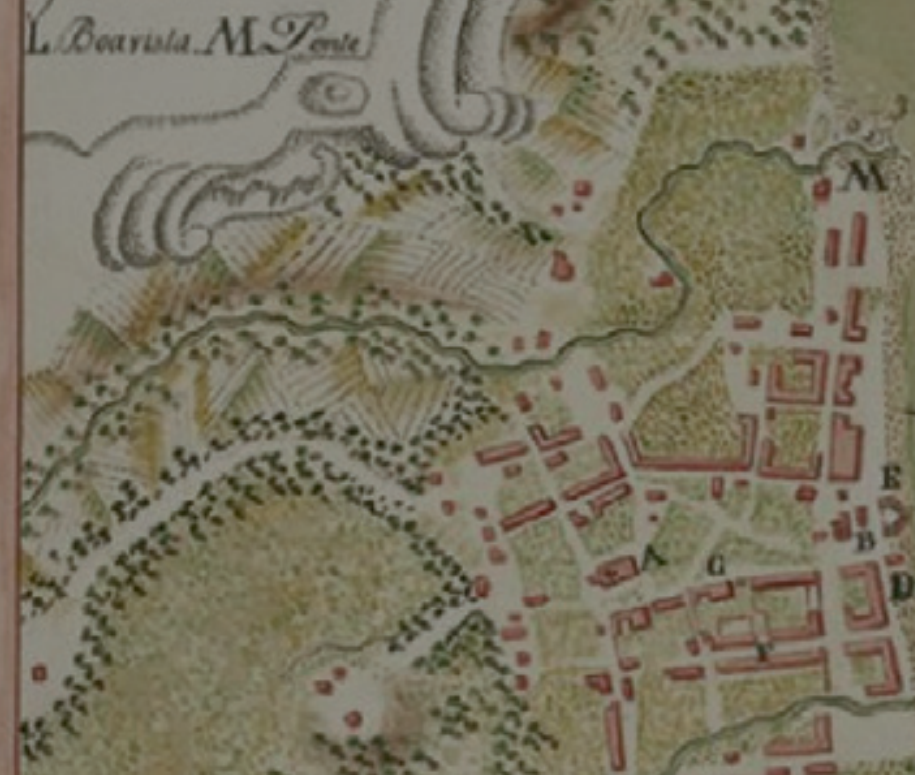
Loarba.M.M.Tere

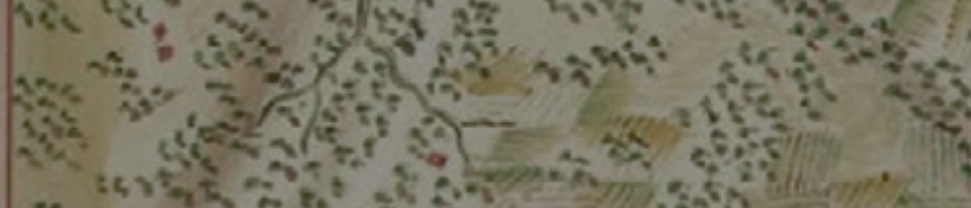

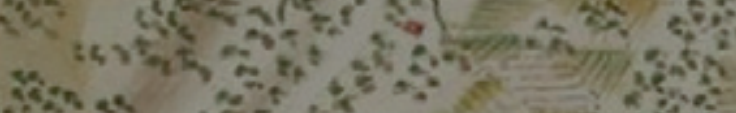

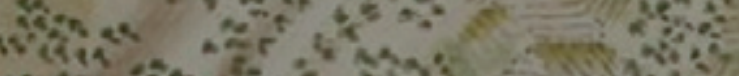

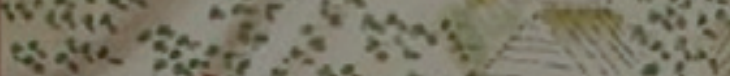

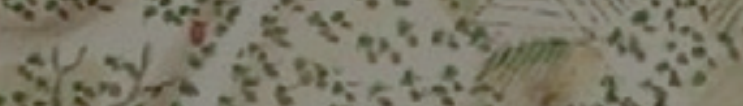

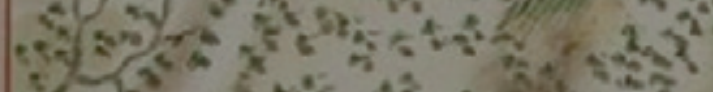

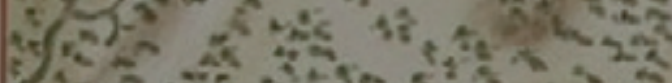

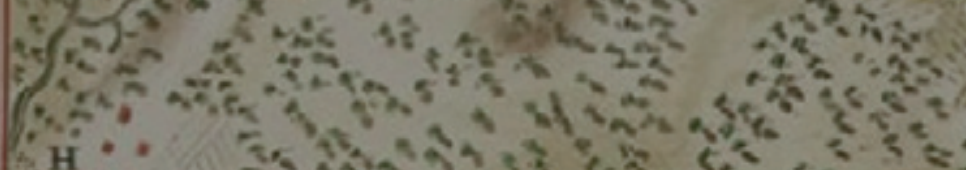

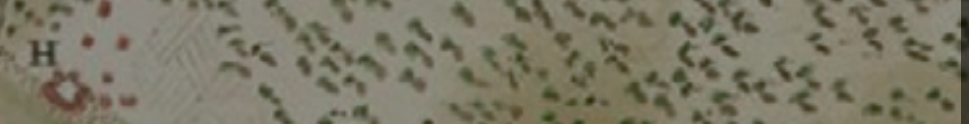




\title{
O PORTO DE FLORIANÓPOLIS: DESENVOLVIMENTO ECONÔMICO DE UMA OCUPAÇÃO ESTRATÉGICA
}

\author{
THE PORT OF FLORIANOPOLIS: ECONOMIC DEVELOPMENT OFA \\ STRATEGICTAKEOVER \\ EL PUERTO DE FLORIANÓPOLIS: DESARROLLO ECONÓMICO DE UNA \\ OCUPACIÓN ESTRATÉGICA
}

\author{
Milton Luz da Conceição
}

\section{Resumo}

Este texto manifesta uma característica especial do processo de ocupação e urbanização da Ilha de Santa Catarina. A fundação de cidades no processo português de urbanização tem uma motivação econômica; na ocupação da Ilha de Santa Catarina, no entanto, a motivação foi estratégica militar. Passada a fase de ocupação defensiva, tendo o polinucleamento como estratégia, o núcleo inicial, Nossa Senhora do Desterro, se destacou sobre todos os outros pelas características que a originaram, de ser um porto natural em águas mansas, próximo ao continente. Seguimos dentro do processo de formação da atual cidade de Florianópolis, sucessora dessa ocupação inicial, e detentora de morfologia que denuncia essa origem.

Palavras-chave: Porto. Fundação de cidades. Desenvolvimento econômico. Motivação estratégica.

\begin{abstract}
This paper attempts to demonstrate a foundational feature of the occupation and urbanization of the island of Santa Catarina. Most of the foundation of the Portuguese cities urbanization had an economic motivation. Instead, the occupation of the island of Santa Catarina motivation was military strategic. Passed this first phase, the first seed city, "Nossa Senhora do Desterro", stand out above all others, because of its generating element, the natural harbor of calm waters, near the mainland. We follow the text studying this port within the current formation of Florianopolis process because knowing the different types of origin in the formation of a city, it will be easier to detect on the maps of their current morphology, where the origin of it.
\end{abstract}

Keywords: Port. Founding cities. Economic development. Strategic motivation.

\begin{abstract}
Resumen
Este texto intenta demostrar un rasgo fundamental en el proceso de urbanización y ocupación de la isla de Santa Catarina, al sur de Brasil. La mayor parte de la fundación de ciudades en el proceso de urbanización portugués tuvo una motivación económica; no obstante, en la ocupación de la isla de Santa Catarina la motivación fue estratégica militar. Pasada la primera fase de ocupación defensiva, el núcleo inicial, Nossa Senhora do Desterro, se destacó sobre los demás por las características de su origen, un puerto natural de aguas mansas, próximo al continente. El texto sigue en el proceso de formación del actual Florianópolis, en la que se detecta en la morfología actual el origen de su urbanización.
\end{abstract}

Palabras clave: Puerto. Fundación de ciudades. Desarrollo económico. Motivación estratégica. 


\section{Introdução}

Como observou Charles-Edouard Jeanneret-Gris (LeCorbusier),

"Os processos de evolução urbana precisam ser observados 'in loco', já que cada território possui características especiais determinantes em seu processo de formação" (LE CORBUSIER, 1984).

Uma leitura superficial, com base em fenômenos idênticos, em latitudes distintas, mascara processos que conduzem a conclusões equivocadas. Estas provocam ações estatais mais equivocadas ainda, já que o que parece pode não o ser. Em se tratando da atualidade brasileira, para se entender a dinâmica de um território e seu processo de urbanização, é necessário analisar as características e as relações econômicas, sociais e ambientais vigentes desde o surgir histórico, passando pela evolução da região até sua presença como Estado Federativo.

Inegavelmente, o processo de urbanização no mundo ocidental iniciou-se na metade do século XIX, entendendo-se por processo de urbanização a migração acelerada do homem do campo para a cidade, consequência da intensificação do modelo industrial.

"Antes de 1850, [...] nenhuma sociedade poderia ser considerada como predominantemente urbana" (SOUZA, M. A. in SANTOS, M. 1994).

Nos países de industrialização tardia, o fenômeno ocorreria de acordo com sua inserção nesse processo.

No Brasil, podemos dizer que o processo de industrialização iniciou-se com um moroso deslocamento dos grandes fazendeiros de café para a cidade de São Paulo e algumas indústrias se instalando, no mesmo ritmo, na Região Sudeste, em fins do século XIX. O aceleramento da industrialização somente ocorreria por volta da década de 30 , do século XX, comas políticas deflagradas por Getúlio Vargas em sua "fábrica de fábricas".

Na Ilha de Santa Catarina, a urbanização viria sem processo de industrialização, condições históricas precedentes nos fizeram pular etapas. Nossa estrutura de ocupação junto a diversos fatores, históricos, socioeconômicos e culturais, induziu um processo de colonização (século XVIII) baseado numa ocupação territorial polinucleada que isolou o colono em pequenos núcleos no interior da ilha, alheios a mudanças ocorridas no mundo. O núcleo principal dessa ocupação, a atual cidade de Florianópolis, manteve um lento processo de atualização, tendo o porto como elemento de conexão com o exterior. Essa condição deu a esse equipamento também o papel de locomotor da economia. O crescimento populacional apresentava-se vegetativo, recebendo, de tempos em tempos, grupos de imigrantes. Esse quadro perdurou por muitos anos, gerando uma economia de discreto dinamismo, mais voltada ao local e ao comércio costeiro. 


\section{Uma ilha polinucleada, base de uma urbanização estratégica e não econômica.}

Depois de um período de conturbada ocupação, a Coroa portuguesa sentiu a necessidade de um projeto estratégico-militar para a consolidação de sua presença na costa sul do Brasil. Elegeu para essa tarefa o brigadeiro José da Silva Paes e, como "ponta de lança" da base física do projeto, a Ilha de Santa Catarina. Em 1738, o brigadeiro desembarcou no território escolhido. Seu projeto estratégico apoiou-se em dois pilares: um sistema de fortalezas para defesa militar e a fundação de vários núcleos, em locais previamente escolhidos, para ocupação territorial.

O envio de colonos para viabilizar o projeto começou a partir de 1748, quando aportaram na ilha as primeiras 50 primeiras famílias oriundas do arquipélago dos Açores. Em 1749, mais 47 famílias açorianas; entre 1750 e 1753, mais 4.000 colonos reforçaram o contingente que se completaria com 600 pessoas chegadas da ilha da Madeira, em 1756.

Em dez anos, oito núcleos seriam fundados na ilha por Silva Paes, e mais três no continente próximo. É bom lembrar que, ao contrário de outras ocupações insulares, esse projeto foi favorecido não somente pelos anos avançados na construção do mundo ocidental, mas também pelas dimensões mais reduzidas do território de Paes, pela proximidade do continente, e pela não presença de nativos agressivos.

As expedições para fundação dos núcleos saíam do núcleo central já composta por um vigário, alguns soldados e os colonos. Segundo reza a "Provisão Régia" de 9 de agosto de 1747, na chegada ao local escolhido, a primeira construção deveria ser a igreja, com seu largo frontal.

A partir deste núcleo central já consolidado (Nossa Senhora do Desterro, 1675), o brigadeiro José da Silva Paes percorreu a ilha com uma expedição e fundou, entre 1750 e 1772, as vilas de Nossa Senhora das Necessidades (1750), sobre um núcleo já existente; Nossa Senhora da Conceição (1751);Nossa Senhora da Lapa(1756); São João do Rio Vermelho e Sant'Anna da Armação (1772), seguiu o processo até 1806, completando os seis núcleos que formariam a primeira rede polinucleada, que foi a base da ocupação territorial da Ilha de Santa Catarina. No ano de 1830, a ilha já tinha 18 igrejas e seus respectivos povoados. No continente próximo, foram fundados, ainda como parte desse projeto, os núcleos de Nossa Senhora do Rosário da Enseada de Brito, São José da Terra Firme e São Miguel da Terra Firme, entre 1748 e 1756.

A colonização açoriana foi um fracasso no plano econômico como seria inevitável. Isolados em pequenos núcleos no interior da ilha com um litoral deserto, sem conhecimentos próprios para o trabalho agrícola em terras desconhecidas, estavam condenados a um trabalho de subsistência, porque não tinham mercado consumidor para sua produção (Ribeiro, 1999).

A produção de mandioca, em substituição ao trigo, a que estavam familiarizados, a pesca e o artesanato foram as ativida- 
des econômicas a que iriam dedicar-se esses colonos. Essa divisão do trabalho refletida sobre o território daria a esses núcleos uma morfologia característica. Uma aglomeração de casas homogêneas na pobreza, ao redor do rocio e fazendolas ao redor de um engenho de mandioca, nos arrabaldes.

Os açorianos absorveram com facilidade os costumes e a cultura dos escassos nativos e, em poucos anos, pareciam-se mais a "matutos", ajustando se a um modo de vida mais "indígena", renunciando a seus traços culturais. Isso não impediu que fossem esses imigrantes os responsáveis pelo primeiro fluxo de desenvolvimento da Ilha de Santa Catarina.

Credita-se o fracasso econômico dessa ocupação à proibição de comércio exterior, como manifestou o navegador russo Krusenstern, de passagem pela ilha em 1811:

No continente, como em toda a ilha, o solo é notavelmente fértil. Excelente café e açúcar são cultivados aqui. Mas como os navios estrangeiros somente podem comprar à vista, e nenhum dos habitantes deste núcleo pode mandar seus produtos para Europa; a perspectiva de comércio é praticamente nula (KRUSENSTERN apud BERGER, 1979).

Esse relato do capitão Krusenstern, do navio "Nadesha", integrante de uma expedição oficial do governo russo em 1803, revela a proibição dos portos brasileiros de fazer comércio com nações estrangeiras até 1808. A partir daí,a permissão foi dada somente aos portos do Rio de Janeiro e de Salvador, alijando os outros.

Mesmo depois de 1808, o território insular e suas adjacências continentais continuaram com uma produção agrícola de subsistência. Os parcos excedentes seguiam pelo porto de Nossa Senhora do Desterro, depois, Florianópolis, para outros portos do litoral brasileiro, formando lentamente uma dinâmica de navegação regular comercial costeira. Essas considerações demonstram a pouca importância que a corte dava à economia nesse território.

Quanto ao projeto estratégico militar de defesa da costa, o fracasso não foi menor, permitindo a invasão e ocupação da Ilha de Santa Catarina pelos espanhóis, em 1777. A concepção das fortalezas, mesmo ineficazes, deixou marcas sobre o espaço físico, alterou a paisagem natural e ocupou, de maneira definitiva, o imaginário dos habitantes.

A reflexão sobre a ilha e a costa catarinense ter sido povoada em função de necessidades estratégicas e não de objetivos econômicos, tese central deste texto, baseia-se fundamentalmente nas questões expostas acima, que acreditamos distintas de outras regiões da colônia.

\section{O porto, elemento colonizador como origem da cidade}

A chegada da colonização portuguesa ao Brasil teve como objetivo maior o comércio com as "Índias" (RIBEIRO,1999).Essa política criou uma estrutura dinâmica que vemos como uma rede urbana do litoral. 
El litoral juega un papel de enorme trascendencia en la organización territorial derivada del proceso colonizador. Los nodos portuarios se configuran como los estructurantes de un "hinterland" interior no siempre profundo y cuya función principal sigue siendo facilitar la expedición de los recursos naturales (MUÑOZ, 1998)².

Em um segundo momento, visto não ser o Brasil o caminho às Índias, o interesse português se voltou à prata peruana, especificamente em dominar a entrada do Rio da Prata, visto nesses tempos como caminho a esse tesouro. É aí que a costa sul do Brasil ganhou importância e, com ela, a llha de Santa Catarina.
2."O litoral joga um papel de enorme transcendência na organização territorial derivada do processo colonizador.

Os complexos portuários se configuram como estruturantes de um "hinterland" intermediário cuja principal função segue sendo facilitar a expedição dos recursos naturais."

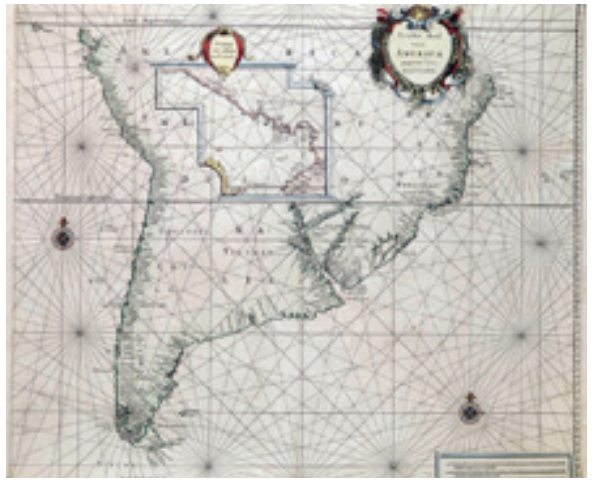

Seguindo na intenção de ver o porto como destacado elemento colonizador na origem do núcleo de Nossa Senhora do Desterro/Florianópolis, acreditamos na sua função estratégico-militar como motivadora de sua implantação. Por isso não podemos analisar de maneira isolada os dados a respeito desse episódio, mas sim como dados conectados por essa conjuntura que, por sua vez, está sujeita a um processo de origem social. Os demais núcleos, elementos geradores de cidades, que vão surgir no continente ao longo da costa são também consequências desse processo.

O interesse de navegadores europeus por esses mares era anterior à chegada oficial dos portugueses. O primeiro relato conhecido da presença de navegadores europeus na Ilha de Santa Catarina é atribuído à expedição do italiano Sebastião Caboto, em 1526. Nesse documento, Caboto ressaltava a boa qualidade, para atracação, de suas baías protegidas devido à proximidade ao continente, além da abundância de água e víveres. Outro navegador, Diego Ribeiro, incluiu a ilha no mapa-múndi, em 1529. Porém a presença mais importante foi a do espanhol Alvar Nuñez Cabeza de Vaca que, em 1538,organizou uma expedição partindo da Ilha de Santa Catarina em direção oeste, em busca da prata peruana, o que levou ao descobrimento das cataratas do Iguaçu, em 1542. A ocupação oficial de esse território insular dar-se-ia em 1673, por obra do colonizador Francisco Dias Velho. O fundador do povoado de Nossa Senhora do Desterro, a atual Florianópolis, encontrou a ilha completamente deserta, diferindo do relato de Cabeza de Vaca, que fez menção à boa receptividade dos nativos:

"Tanto para enseñar los caminos como para servilos em otras necesidades" (CABEZA DE VACA, 1987).
Figura 1 - a) Mapa da América do Sul (Colom;Doncker, Amsterdã, 1663) mostrando o Rio da Prata como um grande canal até o Peru.

b) Mapa da costa sul do Brasil (Alonso de Santa Cruz, 1540) destacando a llha de Santa Catarina a meio caminho entre o Rio de Janeiro e a foz do Rio da Prata. 
É possível que o fenômeno seja idêntico ao rápido e abrupto descenso demográfico apontado na ilha de Cuba pelos primeiros espanhóis, devido à fuga indígena como consequência da exploração escravagista. A presença indígena foi ratificada por meio de vestígios, além do relato do alemão Hans Staden (2007), que descreveu uma aldeia na Ilha de Santa Catarina, em 1549.

O pequeno enclave de Dias Velho se instalou no centro da costa oeste da ilha, no ponto mais próximo ao continente, sobre uma ponta que divide o mar em duas baías. A morfologia da ocupação seguiu o princípio comum aos traçados insulares portugueses do período: uma capela em frente à linha da costa, com um largo entre ela e o mar, ladeada pelas casas dos colonos. Sobre a oficialização desse evento, bem como a legalização de suas terras, relatou Pedro Taques:

Em 1675 esteve em pessoa nesta vila o capitão Francisco Dias Velho com novas reinvindicações do novo assentamento onde esteve por três anos, e voltou em 1679, no requerimento feito nesta vila de Santos ao Governador da Capitania, pedia em sesmaria duas léguas em quadro na ilha de Santa Catarina ao largo da costa onde já estava edificada a igreja de "Nossa Senhora do Desterro," e mais meias légua de uma lagoa onde já havia algum cultivo, e mais duas léguas em terra continental diante do primeiro povoado onde já tinha também alguma plantação, outra légua frente aonde chamam "Bogio" e outras duas léguas começando no rio Araçatuba. Tudo se concedeu por sesmaria em atenção aos serviços prestada a Sua Majestade pela nova população da ilha de Santa Catarina. Esta representação em sesmaria está registrada na notaria da "Provedoria da Fazenda Real de São Paulo," no livro de registros de sesmarias $n^{\circ} 13$, título 1673, pagina 781 (TAQUES citado por PAULI, 1966).

Duas décadas depois, a empreitada de Dias Velho foi invadida e saqueada por piratas. O colonizador vicentista foi morto junto com sua família, colonos e escravos. A ilha ficaria entregue a poucos colonos sobreviventes e sua ocupação somente seria retomada e impulsionada a partir da chegada do brigadeiro Paes Leme, cuja ação já foi relatada neste texto.

Como já visto, com Silva Paes chegaram novos colonos, desta vez, oriundos dos arquipélagos dos Açores e da Madeira. O impulso trazido pela colonização açoriana começou a render alguns frutos ao final do século XVIII, depois de cem anos de agricultura de subsistência. Com a abertura dos portos de Rio de Janeiro e Salvador (1808), intensificou-se a navegação na costa catarinense, dando ao porto certo dinamismo e alguma importância, o que faria surgir o primeiro mercado da que passou a ser chamada Vila de Nossa Senhora do Desterro.

A circulação de mercadorias iniciou uma nova fase na economia. Nota-se, neste período, o acréscimo de escravos africanos ao plantel do senhorio local, triplicando seu número para 3.137 , numa população total de 12.483 pessoas em toda a ilha, segundo dados de 1810 (PAULI, 1978). 
A Independência brasileira (1822) levou novos ares e o espaço foi perdendo suas características de "vila militarizada" para ter atividades civis e integrar-se num contexto econômico mais propício para a expansão de sua trama urbana.
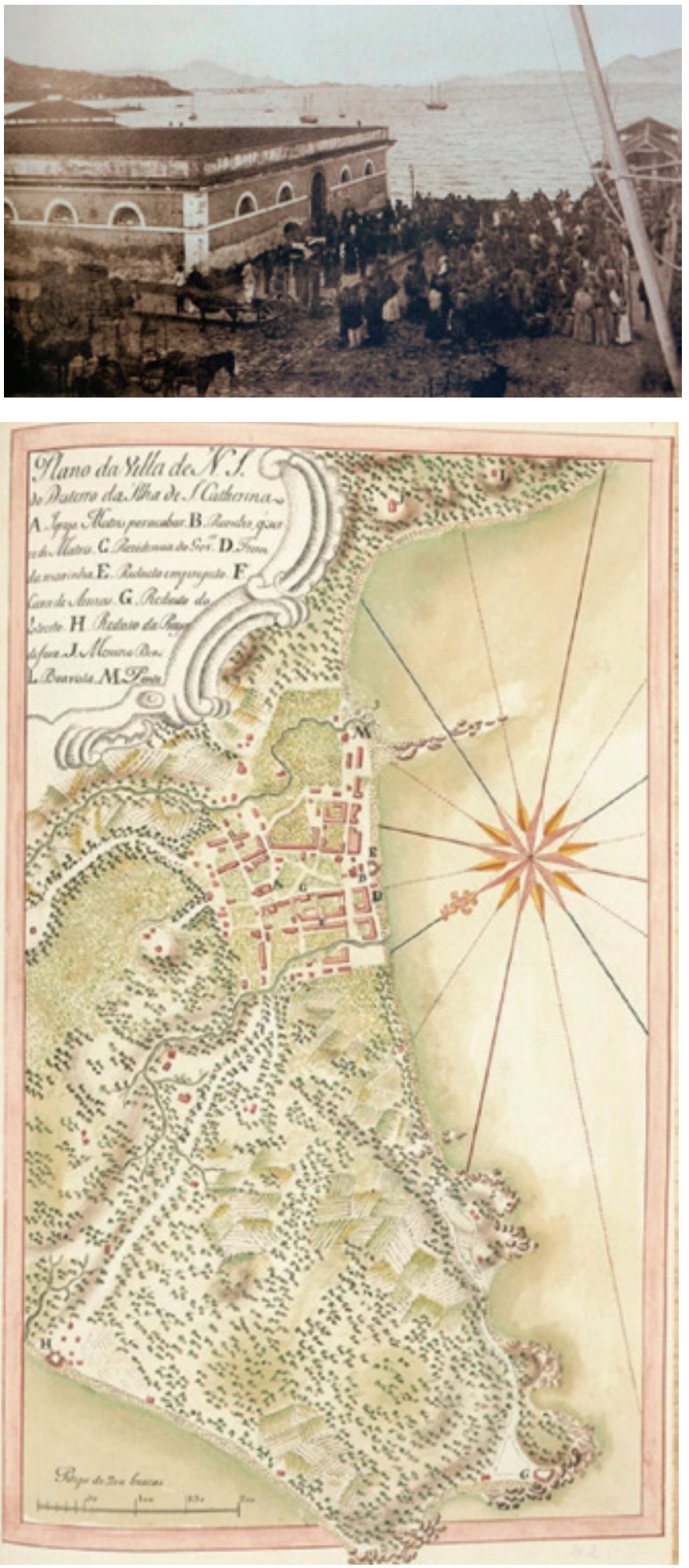

Figura $2 \bullet$ Mercado junto ao mar, ao ar livre, da vila de Nossa Senhora do Desterro no século XIX.

Fonte: www.ricmais.com.br capturado em 11.05.2016

Figura $3 \bullet$ - Mapa da primeira década do século XIX mostra a trama urbana ao redor do porto.

Fonte: Acervo do Arquivo Municipal de Florianópolis. 
O período de comércio mais intenso no porto durante o século XIX foi registrado entre 1830 e 1880. Contribuiu para esse desenvolvimento a instalação da Província de Santa Catarina e a chegada dos primeiros imigrantes europeus não ibéricos. Esses novos colonos chegaram a todo o litoral catarinense em busca de sobrevivência, fugindo das mudanças políticas e econômicas europeias. Darcy Ribeiro (1999) denomina o fato “imigração tardia".

O grupo de imigrantes alemães, italianos, gregos e sírios, em sua maioria, não se dedicavam as atividades agrícolas, como era a intenção do Estado brasileiro. Permaneceram já na agora vila de Nossa Senhora do Desterro, junto ao porto, dedicando-se à importação e exportação, e ao comércio. Foram também responsáveis pelo primeiro grande impulso no comércio varejista local, principalmente no setor de tecidos e alimentação. A economia cresceu, formando uma primeira elite urbana, na qual estavam presentes comerciantes bem-sucedidos, proprietários de meios de transporte, funcionários públicos de relevância, militares de alta patente e os primeiros profissionais liberais. A estrutura social dos pequenos núcleos do interior da ilha tinha nos produtores agrícolas suas figuras mais destacadas. Estabeleceu com o porto de Nossa Senhora do Desterro uma relação de centro-periferia, abastecendo a população local e exportando os excedentes.

A liberdade dada por parte do poder central da colônia na administração dos excedentes, que já se iniciara aos finais do século XVIII, além de deixar transparecer a pouca importância dada à economia local, exerceria papel determinante na conformação do litoral sul do Brasil, com uma posição destacada para o comércio de alimentos. A cidade do Rio de Janeiro era, nesta época, a maior importadora dos produtos do litoral sul, porém a abrangência dessa rota comercial chegava ao litoral norte brasileiro e, ao sul, a Montevidéu e Buenos Aires (MAMIGONIAN citado por CAMPOS, 1991).

A importância dessa produção e do comércio se manifesta no relato do governador da Capitania de Santa Catarina, tenente-coronel João Alberto Ribeiro, no final do século XVIII:

En 1796 la población de la capital era de 3.757 habitantes de los cuales 2.652 blancos, 110 forros, $^{3}$ y 99 esclavos, más 1.027 militares. Había 18 tiendas de telas, con productos variados desde el hilo del algodón hasta botones de oro y plata, lienzos blancos de lino y algodón, lienzos de tabaco, lanas blancas y de colores, calcetines de lino y seda, mantas de tela, etc.; 43 tabernas vendían los alimentos, y sus mercancías eran aceite, aguardiente, algodón, mantequilla, pasas de uva, vino, té, etc. El puerto este año recibió 116 navíos, venidos del "Rio de Janeiro," "Bahia," "São Sebastião," "Pernambuco," "Goitacazes," "Parati," "Ilha Grande,, "Paranagua," "São Francisco," "Laguna," "Rio Grande," "Santos" y "Biscaia." Los artesanos que atendían a la población eran: ocho sastres, diecinueve zapateros, cuatro peluqueros, cuatro herreros, dos carpinteros, y uno de cada de las siguientes profesiones: cerrajero, hacedor de embudos, pintor. Encontraban aun dos tiendas de pro-
3. Forro: escravo alforriado

Cadernos de Arquitetura e Urbanismo, v.21, n.29, 20 sem. 2014 
ductos para la agricultura y ganadería, dos curtidores, y dos boticas. La exportación era variada: harina de mandioca, arroz, maíz, frijoles, miel, aguardiente, melaza, azúcar, grasa de ballena, madera, pez seco, aceite de pez, cebollas, cuero, cal, tejas, ladrillos, etc."(citado por PELUSO JUNIOR, 1991).

A diversificada divisão social do trabalho estabelecendo um grande número de profissionais na ilha evidenciava que a intenção portuguesa era o desenvolvimento de Nossa Senhora do Desterro para ocupar um espaço destacado na estratégia política e comercial no meio caminho entre o Rio de Janeiro e Buenos Aires, as duas mais importantes cidades da América do Sul de então.

O mercado informal ao ar livre junto à praia, em frente à praça principal (hoje Praça XV de Novembro), sucedânea do largo e frente à igreja matriz, ganhou seu primeiro edifício em 6 de janeiro de 1851 (FIG.4), consolidando, assim, a primeira zona comercial (FIG.5).

A morfologia arquitetônica do edifício, segundo a classificação de Geoffrey Broadbent (2006), denotava sua única intenção com a função, porém sua importância estava na estruturação espacial urbana que, junto à Praça XV de Novembro e o porto, formavam o conjunto ordenador do espaço público da cidade que se consolidava.

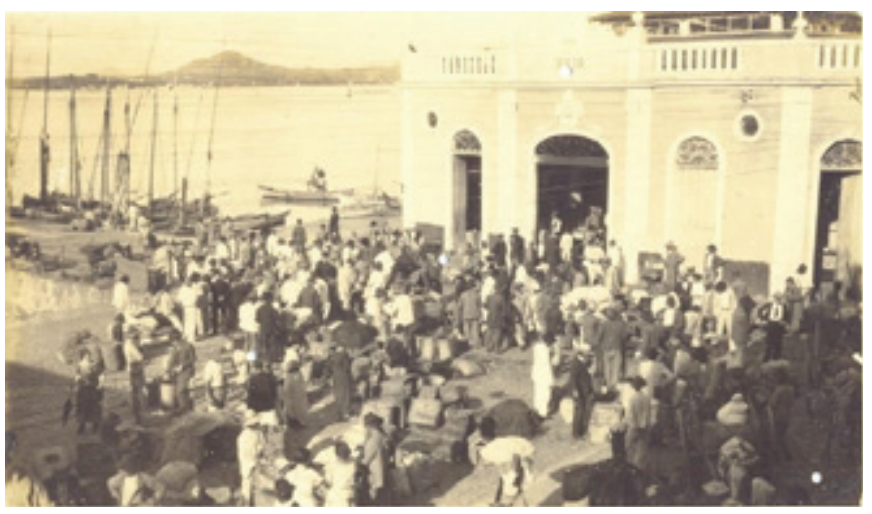

Incorporando-se ao prédio do mercado, esse espaço ampliou-se à direita, junto ao porto, com o prédio da Alfândega, de 1876, que apresenta uma arquitetura próxima ao neoclássico.

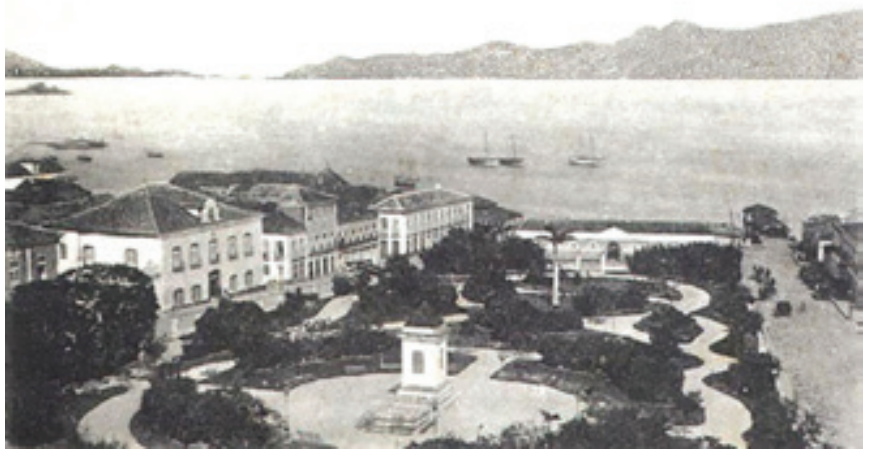

Figura 4 - Edifício do Mercado, inaugurado em 1851.

Fonte: Acervo do Arquivo Municipal de Florianópolis.

Figura 5 • Primeira zona comercial junto à praça, o mercado aparece à direita, junto ao mar.

Fonte: Acervo do Instituto Histórico e Geográfico de Santa Catarina.

Cadernos de Arquitetura e Urbanismo, v.21, n.29, 2º sem. 2014 


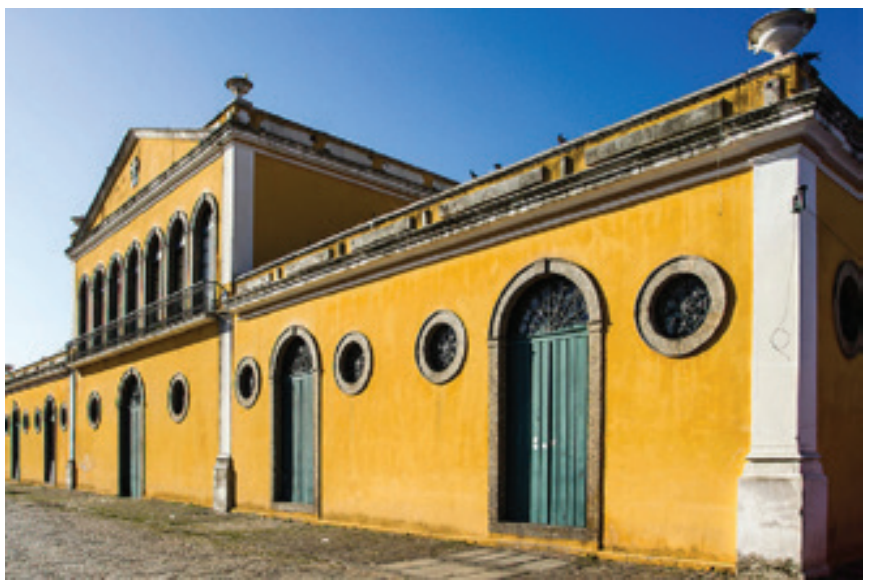

Figura 6 • Edifício da Alfândega (atual), inaugurado em 1876.

Fonte: http://ricardoribas.photoshelter. com/ . (Capturado em 23/05/2016.)

Essa primeira zona comercial se complementava com outros edifícios que tinham característica arquitetônica própria para esse tipo de espaço e tempo. Seu uso era geralmente misto, com a parte superior residencial e o pavimento térreo comercial, como se pode notar na figura 7, cena urbana que mostra a zona de expansão comercial em direção ao norte, em frente ao mar.

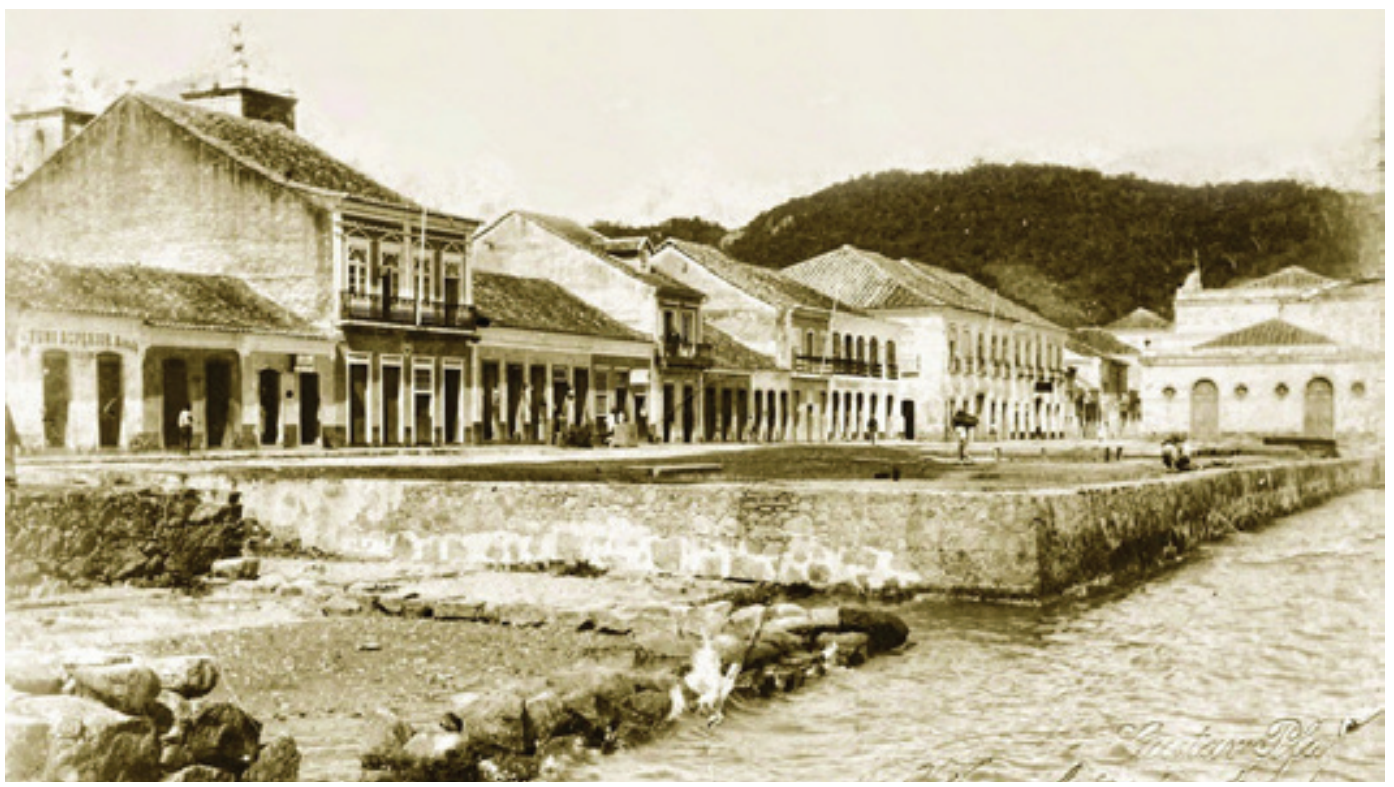

Na segunda metade do século XIX, a praça (FIG. 5) e as 47 ruas e 8 becos adjacentes davam forma a uma trama urbana dentro de um conceito que contemplava espaços de circulação, de comunicação e de trocas, destacando os espaços não edificados no meio construído da cidade. A análise dessa trama indica que o processo de formação da cidade de Nossa Senhora do Desterro teve, nessa praça e no porto, o seu elemento de "origem".

A cidade que ia se consolidando caminhava em três vetores até o início do século XX (FIG. 3). O vetor mais forte, que segue em direção oeste, é formado por três vias principais paralelas
Figura 7 • Foto de 1880 mostra a zona de expansão, com o edifício da Alfândega à direita, ao fundo. No aterro mostrado, seria construído o novo Mercado Municipal.

Fonte: www.velhobruxo.tns.ufsc.br/ Albuns.html . Capturado em 23/05/2016.

Cadernos de Arquitetura e Urbanismo, v.21, n.29, 20 sem. 2014 
ao mar: a primeira (atual Felipe Schmidt), fruto da conexão entre o largo original e a fonte d'água; a segunda, intermediária; e a terceira, junto à orla da baía sul. O segundo vetor aponta para o norte da praça e tem a destacar a via que liga a baia sul à baia norte (atual Rua Esteves Junior). O terceiro vetor, paralelo ao mar, em direção leste, a caminho do Hospital de Caridade (Fig.8). Tal conformação urbana fazia a cidade circular no sentido norte-sul, o que foi alterado na segunda década do século $X X$, quando a cidade passou a circular no sentido leste-oeste, com a inauguração da Ponte Hercílio Luz.
Figura $8 \bullet$ Hospital de Caridade (1940) Fonte: http://fotosantigasflorianopolis. blogspot.com.br/ Capturado em 23/05/2016.
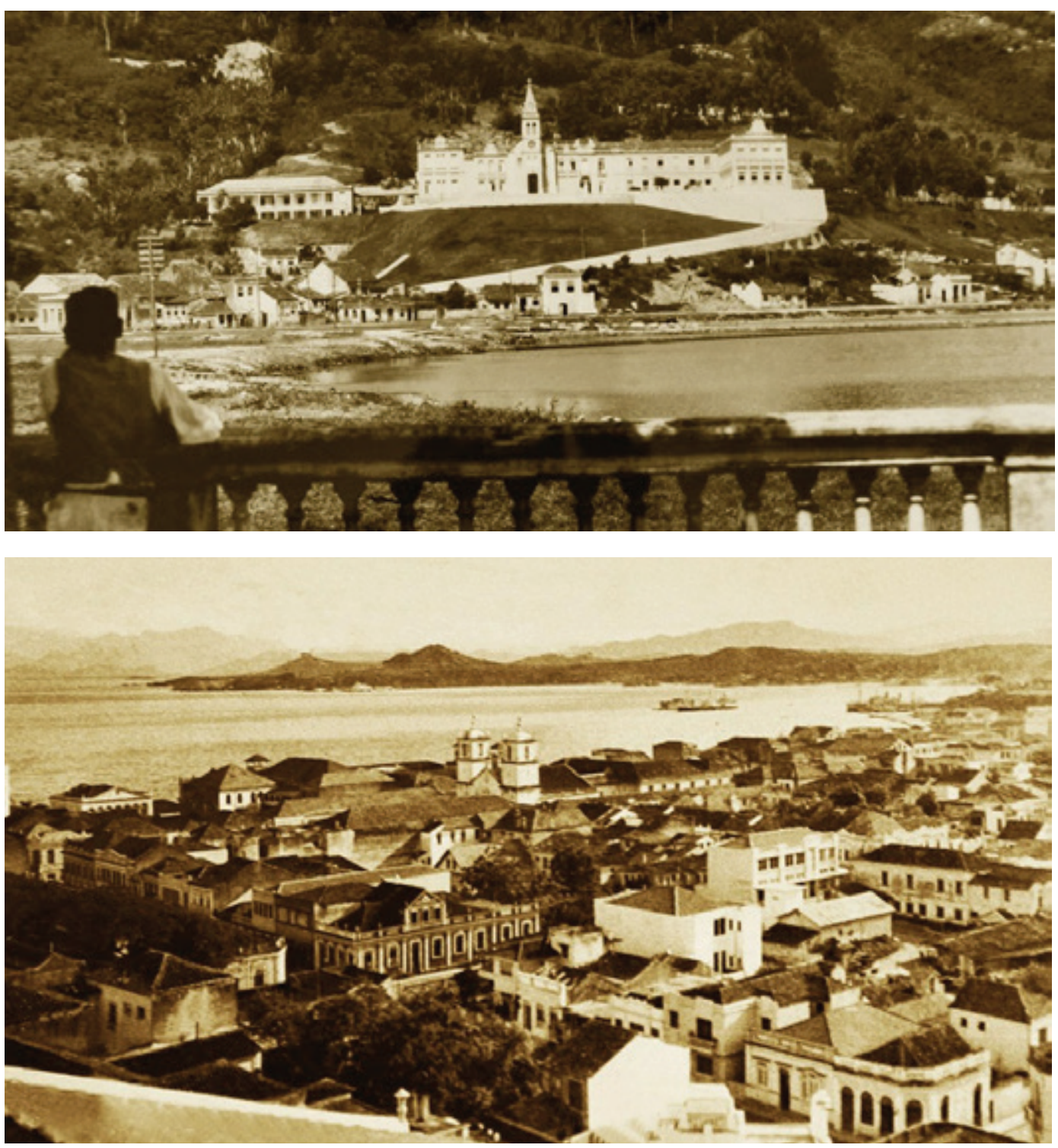

A forma das edificações inicialmente primitiva e de má qualidade construtiva foi adotando, aos poucos, técnicas edificatórias mais avançadas e ganhando formas influenciadas pelas grandes metrópoles de então.
Figura $9 \bullet$ Centro de Florianópolis, destaque para o porto, ao lado direito

Fonte: http://fotosantigasflorianopolis. blogspot.com.br/ (Capturado em 23/05/2016).

Cadernos de Arquitetura e Urbanismo, v.21, n.29, $2^{0}$ sem. 2014 
Assim, o século XIX terminou com as ruas do centro histórico tendo uso comercial e residencial. A tipologia de rua de fachada contínua, formando um corredor, é consequência não só dos costumes da época, mas também da rigorosidade das administrações locais. Os limites entre o espaço público e o privado coincidiam com o plano da fachada, sem nenhuma transição.

Os 14 mil habitantes da cidade entraram no século XX com algumas melhorias de serviço público. A coleta de lixo, iniciada em 1884; o forno incinerador, em 1916; a primeira rede de abastecimento de água, 1910; e a implantação da rede de esgotos, em 1916, daria início à reforma sanitarista promovida pelo governo de Gustavo Richard. O alargamento de ruas e praças, culminando com a inauguração da Ponte Hercílio Luz (1920), complementou a reforma urbana, preparando a entrada na Modernidade da já cidade de Florianópolis.

A mudança do nome da cidade de Nossa Senhora do Desterro, ou simplesmente Desterro, para Florianópolis se deu em consequência da derrotada insurgência contra o governo central de Floriano Peixoto. Durante meio ano, a cidade do Desterro foi sede de uma república independente, formada por revolucionários federalistas dos três Estados do sul, unidos aos também rebelados militares da Marinha do Brasil. Após o fracasso da revolta, o nome da cidade foi trocado como forma de castigo-homenagem ao vencedor, encerrando um dos mais sangrentos episódios da História brasileira.

\section{Considerações finais}

Finalmente, mesmo diante da dificuldade de explicitar em um artigo a abrangência de uma investigação em curso, apresentamos a ideia de se buscar sobre o território da cidade de Florianópolis e, em sua ampliação, a Ilha de Santa Catarina, marcas de uma formação urbana que tem as atividades portuárias e, consequentemente, o mar, como elemento gerador.

Essa urbanização estudada foi, num primeiro momento, um processo estratégico de proteção do território. Em um segundo momento, as atividades econômicas e comerciais cresceram independentemente da vontade do poder central, ganhando certa autonomia e determinando o futuro de um enclave urbano, o qual se tornaria uma das cidades mais importantes do Brasil a partir dos anos 80 do século XX.

Essa importância no cenário nacional se deu a partir da vitória do projeto da economia neoliberal no mundo ocidental, que leva suas cidades a um setor terciário, tendo, no caso especifico de Florianópolis, o "turismo" como sua principal atividade, dentro do processo conhecido como globalização.

Florianópolis é capturada por esse processo com uma rapidez acima da média. As mudanças socioeconômicas, culturais e espaciais são radicais. A dinâmica da cidade acelera, e o consumo de bens e serviços é o grande locomotor dessas transformações. Identificar esses processos por meio dos seus elementos espaciais formadores é a intenção na continuidade deste trabalho. 


\section{Referências}

BERGER, Paulo (Org.). Ilha de Santa Catarina: relatos de viajantes estrangeiros nos séculos XVIII e XIX. Florianópolis: Editora da UFSC; Assembleia Legislativa, 1979.

BROADBENT, Geoffrey. Um guia pessoal descomplicado da teoria dos signos da arquitetura. In: NESBIT, Kate (org.).Uma nova agenda para a Arquitetura: antologia teórica. São Paulo: Cosac Naify, 2006.

CABEZA DE VACA, A. N. Naufrágios e comentários. Porto Alegre: LP\& M, 1987.

CAMPOS, Nazareno José. Terras comunais na ilha de Santa Catarina. Florianópolis: FCC, 1991.

CENTRO DE ASSISTÊNCIA GERENCIAL DE SANTA CATARINA. Evolução histórico-econômica de Santa Catarina: estudo das alterações estruturais (século XVII até 1960). Florianópolis: CEBRAE/CEAG-SC, 1980.

FOTOS ANTIGAS DE FLORIANOPOLIS. http://fotosantigasflorianopolis.blogspot.com.br/

LE CORBUSIER. Planejamento urbano. São Paulo: Perspectiva, 1984.

MUÑOZ, J. M. Barragán. La ordenación del espacio litoral brasileño. In: Anales de Geografía de la Universidad Complutense, n. 18, p. 89-114, 1998.

NOSSO MERCADO. www.ricmais.com.br

PAULI, Evaldo. A fundação de Florianópolis. Florianópolis: Edeme, 1978.

PAULI, Evaldo. História da religião no Estado de Santa Catarina. Florianópolis: IOESC, 1966.

PELUSO JUNIOR, Victor Antônio. A criação da Capitania da Ilha de Santa Catarina. Revista do Instituto Histórico e Geográfico de Santa Catarina, Florianópolis, p. 107-123, jul./dez. 1944.

RIBAS, Ricardo. http://ricardoribas.photoshelter.com/

RIBEIRO, Darcy. O povo brasileiro: a formação e o sentido do Brasil. São Paulo: Companhia das Letras, 1999.

SANTOS, M., SOUZA, M. Adélia, SILVEIRA, M. L. Território: Globalização e Fragmentação. São Paulo. Hucitec, 1994.

STADEN, H. Viagem ao Brasil. São Paulo: Martin Claret, 2007.

VELHO BRUXO. www.velhobruxo.tns.ufsc.br/Albuns.html

Recebido em 08/08/2014

Aprovado em 16/10/2014 